\title{
Oxidation of 4-Chlorophenol by Mesoporous Titania: Effect of Surface Morphological Characteristics
}

\author{
Osmín Avilés-García, ${ }^{1}$ Jaime Espino-Valencia, ${ }^{1}$ Rubí Romero, ${ }^{2}$ \\ José Luis Rico-Cerda, ${ }^{1}$ and Reyna Natividad ${ }^{2}$ \\ ${ }^{1}$ Facultad de Ingeniería Química, Universidad Michoacana de San Nicolás de Hidalgo, Edifico V1, \\ Ciudad Universitaria, 58060 Morelia, MICH, Mexico \\ ${ }^{2}$ Centro Conjunto de Investigación en Química Sustentable, UAEMéx-UNAM, Km 14.5 Carretera Toluca-Atlacomulco, \\ San Cayetano, Piedras Blancas, Toluca, MEX, Mexico
}

Correspondence should be addressed to Jaime Espino-Valencia; jespinova@yahoo.com.mx and Reyna Natividad; reynanr@gmail.com

Received 28 February 2014; Accepted 1 April 2014; Published 27 April 2014

Academic Editor: Wei Xiao

Copyright (C) 2014 Osmín Avilés-García et al. This is an open access article distributed under the Creative Commons Attribution License, which permits unrestricted use, distribution, and reproduction in any medium, provided the original work is properly cited.

\begin{abstract}
Mesoporous nanocrystalline anatase was prepared via EISA employing CTAB as structure directing agent. The drying rate was used as a key synthesis parameter to increase the average pore diameter. The resultant mesoporous crystalline phases exhibited specific surface areas between 55 and $150 \mathrm{~m}^{2} \mathrm{~g}^{-1}$, average unimodal pore sizes of about 3.4 to $5.6 \mathrm{~nm}$, and average crystallite size of around 7 to $13 \mathrm{~nm}$. These mesophases were used as photocatalysts for the degradation of 4-chlorophenol (4CP) with UV light. Under the studied conditions, the mesoporous anatase degraded 100\% 4CP. This was twice faster than Degussa P-25.57\% reduction of chemical oxygen demand (COD) value was achieved.
\end{abstract}

\section{Introduction}

$\mathrm{TiO}_{2}$ is well known as the photocatalyst by excellence. It has been successfully applied to degrade and mineralize a vast amount of hazardous compounds in both air and water [1$5]$, under mild reaction conditions (low temperature and atmospheric pressure). Within photocatalysis area, it has been widely accepted that the catalyst feature determining its activity is the crystalline structure. Although this is true, other surface characteristics should not be completely left aside. This work aims to report the effect of surface morphological characteristics on mesoporous nanocrystalline anatase activity. The synthesis of the material was conducted by evaporation induced self-assembly approach (EISA). This method was elected since it is a powerful synthesis method to design technologically relevant and functional oxides in the fiber, particle, and film form at the nanoscale [6-9]. The method relies on using very dilute surfactant initial concentration from which a liquid crystalline mesophase is gradually developed upon solvent evaporation. The slow coassembly between the inorganic network and the liquid crystalline phase leads to the formation of long-range order of well-defined mesostructures. The preparation of mesoporous titania particles by EISA has been studied by independent research groups [10-13]. It is expected that a change in size, shape, and dimensions of the mesopore $\mathrm{TiO}_{2}$ modifies the accessibility, adsorption, and diffusion of guest molecules within the pore network, thereby achieving further degradation. The photocatalytic activity of the synthesized $\mathrm{TiO}_{2}$ was tested in the degradation of 4-chlorophenol (4CP).

Chlorinated aromatic compounds are a class of compounds widely used and constitute a particular group of priority pollutants. This is mainly due to their numerous origins (pesticide, paint, solvent, pharmaceutics, wood preserving chemicals, coke oven, and pulp industries) $[14,15]$ and toxic effects. They can be found in ground water, wastewater, and soil. In particular, chlorophenols (CPs) pose serious ecological problems as environmental pollutants due to their 
high toxicity, recalcitrance, bioaccumulation, strong odor emission and persistence in environment, and suspected carcinogen and mutagen effect on the living $[16,17]$. The photocatalytic degradation of chlorinated phenols in $\mathrm{TiO}_{2}$ suspensions has been studied by many investigators [1824]. The results show that phenolic compounds are degraded completely to $\mathrm{CO}_{2}$ and $\mathrm{H}_{2} \mathrm{O}$ through a mechanism involving hydroxylation of the aromatic ring. In particular, 4chlorophenol (4CP) has been accepted as the standard pollutant for heterogeneous photocatalysis. The photocatalytic degradation of $4 \mathrm{CP}$ has been the topic of many investigations [25-29], and the kinetics of the photocatalytic degradation has been extensively studied [30-36]. Despite this vast literature, it still remains unclear whether there is an interaction or not between $4 \mathrm{CP}$ degradation and surface morphological characteristics of the employed photocatalyst. Therefore, it is relevant to conduct this study not only in the context of $4 \mathrm{CP}$ degradation but also in general within photocatalysis area.

\section{Experimental}

2.1. Materials and Synthesis. Titanium (IV) ethoxide $\left(\mathrm{C}_{8} \mathrm{H}_{20} \mathrm{O}_{4} \mathrm{Ti}, 80 \%\right.$ Aldrich) and titanium (IV) butoxide $\left(\mathrm{C}_{16} \mathrm{H}_{36} \mathrm{O}_{4} \mathrm{Ti}\right.$, 97\% Aldrich) were used as precursors. Hexadecyltrimethylammonium bromide, denoted as CTAB $\left(\mathrm{C}_{19} \mathrm{H}_{42} \mathrm{NBr}, 99 \%\right.$ Sigma $)$, was used as the structure directing agent (SDA). Ethanol (99.6\%, Sigma-Aldrich) was used as organic solvent. Nitric acid (65.2\%, Sigma-Aldrich) was used as catalyst.

The synthesis was performed as follows. An alcoholic solution of the precursor was prepared. This solution was added to the SDA under vigorous stirring, and then nitric acid was added dropwise. The resultant solution was stirred at room temperature for $3 \mathrm{~h}$ and then was dried at room temperature. Samples with different drying rates were placed in a rotary evaporator at $100 \mathrm{rpm}$ (Heidolph G3 model) using oil as a heating medium. The synthesized powders were then calcined at $350^{\circ} \mathrm{C}$ and $400^{\circ} \mathrm{C}$. It is worth clarifying that samples calcined at $350^{\circ} \mathrm{C}$ were first calcined at $300^{\circ} \mathrm{C}$ for 1 hour and then at $350^{\circ} \mathrm{C}$ for 4 hours with controlled heating and cooling rate of $1^{\circ} \mathrm{C} \mathrm{min}{ }^{-1}$ to remove the SDA. The same heating rate was used for the samples calcined at $400^{\circ} \mathrm{C}$. The molar ratio of the as prepared samples was 1 precursor : 3.55 $\mathrm{HNO}_{3}: 0.018 \mathrm{CTAB}: 18.71$ ethanol.

2.2. Characterization. Mesoporous titania samples were analyzed by X-ray diffraction (XRD) in a Bruker D8 Advanced diffractometer with $\mathrm{Cu} \mathrm{K} \alpha$ radiation and a LynxEYE detector. BET surface areas and $\mathrm{N}_{2}$ adsorption-desorption isotherms were obtained in an Autosorb-1 Quantachrome. Before measurements, samples were degassed at $250^{\circ} \mathrm{C}$ for $2 \mathrm{~h}$. TEM images were taken with a JEOL-2100 $200 \mathrm{kV} \mathrm{LaB6}$ filament. The morphology and particle size of the mesophases were inspected with a SEM JEOL JSM-6510LV.

2.3. Heterogeneous Photocatalytic Oxidation of 4CP. Photocatalytic degradation studies of $4 \mathrm{CP}$ were performed in a batch photoreactor of cylindrical shape (see Figure 1). The

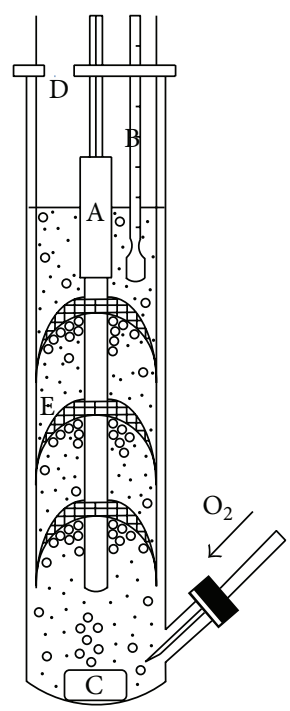

FIGURE 1: Experimental set-up. (A) UV lamp, (B) thermometer, (C) magnetic stirrer, (D) gas outlet and sampling, and (E) oxygen trap.

photoreactor was provided with ports in the lower and upper section for the inlet and outlet of gases and for sampling. Mesoporous titania samples were placed in the glass reactor under continuous stirring $(1000 \mathrm{rpm})$. The total reaction volume was $30 \mathrm{~mL}$. Tests were performed using $0.8 \mathrm{~g} \mathrm{~L}^{-1}$ of mesoporous titania at an initial $\mathrm{pH}$ value of 2 and $4 \mathrm{CP}$ initial concentration $[4 \mathrm{CP}]_{0}$ was $0.233 \mathrm{mmol} \mathrm{L}^{-1}$. The $\mathrm{pH}$ adjustment was made by using $0.003 \mathrm{M} \mathrm{HCl}$ solution. The temperature throughout the experiment was kept constant at $20^{\circ} \mathrm{C}$. The UV lamp was placed at the center of the reactor as the source of UV radiation $\left(254 \mathrm{~nm}\right.$ at 0.786 watts $\left.\mathrm{cm}^{-2}\right)$. Oxygen flow of $50 \mathrm{~mL} \mathrm{~min}^{-1}$ was constantly fed at the bottom of the reactor and an oxygen trap was used to increase its residence time. Aliquots samples $(0.5 \mathrm{~mL})$ were withdrawn from the system every 30 minutes during 3 hours. Catalyst was removed before analysis.

At all experiments, the concentration of $4 \mathrm{CP}\left(\mathrm{C}_{4 \mathrm{CP}}\right)$ was determined using UV/Vis spectroscopy in a PerkinElmer Model Lambda 25 UV/Vis spectrophotometer with a wavelength range of $200-360 \mathrm{~nm}$, where the characteristic absorption peak for 4-chlorophenol is located at $280 \mathrm{~nm}$. A calibration curve was constructed from 0 to $0.311 \mathrm{mmol} \mathrm{L}^{-1}$. A determination coefficient of $r^{2}=0.9994$ and a slope of $\varepsilon b=0.0119$ were obtained. The experiments were repeated three times to verify results reliability.

The chemical oxygen demand (COD) value was analyzed with a Hach UV/Vis Model DR-5000 spectrophotometer in order to determine the degree of oxidation of the 4chlorophenol after the photocatalytic tests.

\section{Results and Discussion}

3.1. Catalysts Characterization. The textural properties of the synthesized mesoporous titania with different type of drying are summarized in Table 1 . The mesoporous samples that were dried at room temperature exhibited specific 
TABLE 1: Specific surface area, average pore size, and average crystallite size of mesoporous titania samples with different type of drying.

\begin{tabular}{|c|c|c|c|c|c|c|}
\hline Drying & Precursor & $\begin{array}{l}\text { Sample } \\
\text { ID }\end{array}$ & $\begin{array}{c}\text { Calcination } \\
\quad\left({ }^{\circ} \mathrm{C}\right)\end{array}$ & $\begin{array}{c}\text { Specific } \\
\text { surface area } \\
\left(\mathrm{m}^{2} / \mathrm{g}\right)\end{array}$ & $\begin{array}{l}\text { Average pore } \\
\text { size }(\mathrm{nm})\end{array}$ & $\begin{array}{l}\text { Average } \\
\text { crystallite } \\
\text { size }(\mathrm{nm})\end{array}$ \\
\hline \multirow{4}{*}{ Room temperature } & \multirow{2}{*}{ Titanium ethoxide } & AE3 & 350 & 117 & 3.4 & 7 \\
\hline & & $\mathrm{AE} 4$ & 400 & 71 & 3.4 & 11 \\
\hline & \multirow{2}{*}{ Titanium butoxide } & AB3 & 350 & 99 & 3.4 & 9 \\
\hline & & $\mathrm{AB} 4$ & 400 & 55 & 3.4 & 13 \\
\hline \multirow{4}{*}{ Rotary evaporator } & \multirow{2}{*}{ Titanium ethoxide } & RE3 & 350 & 115 & 3.8 & 9 \\
\hline & & RE4 & 400 & 87 & 4.3 & 11 \\
\hline & \multirow{2}{*}{ Titanium butoxide } & RB3 & 350 & 145 & 4.3 & 8 \\
\hline & & $\mathrm{RB} 4$ & 400 & 108 & 4.9 & 10 \\
\hline
\end{tabular}

TABLE 2: Specific surface area, average pore size, and average crystallite size of mesoporous titania samples with different drying rate in rotary evaporator.

\begin{tabular}{|c|c|c|c|c|c|}
\hline Drying rate & Calcination $\left({ }^{\circ} \mathrm{C}\right)$ & Sample ID & Specific surface area $\left(\mathrm{m}^{2} / \mathrm{g}\right)$ & Average pore size (nm) & Average crystallite size (nm) \\
\hline \multirow{2}{*}{ Fast } & 350 & FR3 & 150 & 3.8 & 8 \\
\hline & 400 & FR4 & 103 & 4.3 & 10 \\
\hline \multirow{2}{*}{ Medium } & 350 & MR3 (RB3) & 145 & 4.3 & 8 \\
\hline & 400 & MR4 (RB4) & 108 & 4.9 & 10 \\
\hline \multirow{2}{*}{ Slow } & 350 & SR3 & 147 & 4.9 & 8 \\
\hline & 400 & SR4 & 108 & 5.6 & 10 \\
\hline
\end{tabular}

surface areas of around $117 \mathrm{~m}^{2} \mathrm{~g}^{-1}$ and average pore size of approximately $3.4 \mathrm{~nm}$. Furthermore, it was observed that the pore diameter remains constant and independent of the calcination temperature. However, the calcination conducted at $400^{\circ} \mathrm{C}$ decreases the specific surface area. Mesoporous samples dried in rotary evaporator exhibited specific surface areas of approximately $145 \mathrm{~m}^{2} \mathrm{~g}^{-1}$ and average pore size of around $4.9 \mathrm{~nm}$. Furthermore, it was observed that the calcination temperature modifies both the specific surface area and average pore diameter. For this type of drying, the best textural properties were obtained using titanium butoxide as precursor. The reactivity of the precursor determines the rates of hydrolysis and condensation to generate the final inorganic oxide structure. Also, the time used in these processes must be sufficient to allow proper interaction between the SDA and the inorganic precursor and generate assembly and organization in regular structures that finally will lead to an ordered mesoporous structure. For this reason, the titanium butoxide as precursor provides a more controlled reactivity and easy handling, thus allowing control of the hydrolysis and condensation reactions, as well as the dimensions of the pores directly related to the size of the alkoxy groups $[37,38]$.

The textural properties of the mesoporous titania phases synthesized with titanium butoxide as precursor and different drying rate in a rotary evaporator are summarized in Table 2. Specific surface areas and average pore size of samples were around $150 \mathrm{~m}^{2} \mathrm{~g}^{-1}$ and $5.6 \mathrm{~nm}$, respectively. When the drying rate became slower (at the same calcination temperature), the average pore diameter is observed to increase. Furthermore, the calcination temperature is found to be the only variable that modifies the specific surface area for these samples. Thus, the influence of the evaporation rate of volatile entities is a key parameter that determines the final mesostructure. The slow and gradual evaporation of the solvent promotes progressive increase in the concentration of the SDA by obtaining the critical micellar concentration (CMC), surfactant micelle formation, and their self-assembly with inorganic species at a specific time where the network is flexible enough leads to greater micellar arrangement [39].

The average crystallite size for all samples was estimated using the Scherrer equation and the FWHM of anatase $\left(\begin{array}{lll}1 & 0 & 1\end{array}\right)$ reflection. Crystal growth increases with a calcination temperature of $400^{\circ} \mathrm{C}$ for all samples. With increasing calcination temperature, the peak intensity of anatase increases (Figure 2), and the width of the (101) peak becomes narrower due to the growth of anatase crystallites. The pore diameter increase is caused by shrinkage of the mesoporous framework at higher temperatures [40].

The XRD patterns of all the mesophases exhibited only the characteristic reflections of anatase at approximately $2 \theta$ of $25^{\circ}, 38^{\circ}, 48^{\circ}, 54^{\circ}, 55^{\circ}$, and $63^{\circ}$. These correspond to the $\left(\begin{array}{lll}1 & 0 & 1\end{array}\right),\left(\begin{array}{lll}0 & 0 & 4\end{array}\right),\left(\begin{array}{lll}2 & 0 & 0\end{array}\right),\left(\begin{array}{lll}1 & 0 & 5\end{array}\right),\left(\begin{array}{lll}2 & 1 & 1\end{array}\right)$, and $\left(\begin{array}{lll}2 & 0 & 4\end{array}\right)$ planes, respectively, of tetragonal titania $[13,41]$ as shown in Figure 2.

Nitrogen adsorption-desorption isotherms and the Barrett-Joyner-Halenda (BJH) pore size distribution of synthesized samples are shown in Figure 3. All of these samples show a IV type isotherm with $\mathrm{H}_{2}$ hysteresis loop, which is representative of mesoporous materials [42].

The TEM images of the mesoporous anatase samples AB4 (dried at room temperature) and SR4 (slow drying rate in rotary evaporator) are shown in Figure 4. For these samples, 


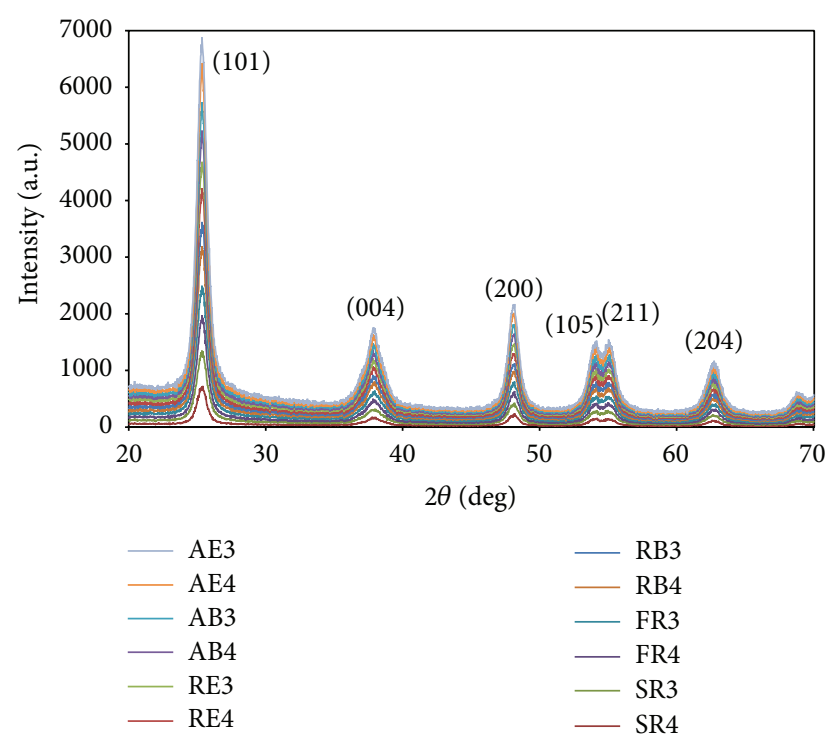

FIGURE 2: XRD patterns of the prepared mesoporous anatase samples.

the anatase crystals were determined to be approximately 13 and $10 \mathrm{~nm}$ in size, respectively. The spacing of $0.35 \mathrm{~nm}$, measured for these two sets of fringes, coincides with $0.352 \mathrm{~nm}$, that is, with the $d$-spacing of $\left(\begin{array}{lll}1 & 0 & 1\end{array}\right)$ type planes in the anatase form of titania, and this was confirmed by XRD data (Figure 2).

Figure 5 shows SEM images of the mesoporous anatase samples SR4 and AB4. The synthesized mesophase SR4 exhibited clusters of approximately $5-10 \mu \mathrm{m}$ while the synthesized mesophase AB4 resulted in the formation of larger clusters of approximately 5-14 $\mu \mathrm{m}$ with irregular shapes.

The reference material Degussa P-25 contains anatase and rutile phases in a ratio of about $3: 1$. Anatase and rutile particles separately form their agglomerates and the average sizes of the anatase and rutile elementary particles are 85 and $25 \mathrm{~nm}$, respectively [43]. Furthermore, their specific surface area is $52 \mathrm{~m}^{2} \mathrm{~g}^{-1}$ and the average crystallite size is $30 \mathrm{~nm}$ [44].

3.2. 4CP Degradation. The mesoporous anatase phases were evaluated in the photodegradation of $4 \mathrm{CP}$. The photoactivity of these samples was compared to that of the reference material Degussa P-25. Figure 6 shows the photocatalytic degradation profiles of 4CP over the mesoporous titania samples and Degussa P-25. All synthesized titania samples showed a higher percentage of degradation than titania Degussa P-25. This may be related to the smaller crystallite size and relatively ordered pore structure of the obtained mesophases. Also, the enhanced photocatalytic activity of the mesoporous titania samples can be partially attributed to the presence of pure anatase phase which is the primary photoactive phase [45].

The mesoporous samples dried at room temperature (Figure 6(a)) and the ones dried in a rotary evaporator (Figure 6(b)) degraded approximately 60-69\% and 75-93\% of $4 \mathrm{CP}$, respectively, after $180 \mathrm{~min}$. Degussa P-25 degraded only $57 \%$ of $4 \mathrm{CP}$ after the same time of exposure to UV
TABLE 3: Initial reaction rates and removal of $4 \mathrm{CP}$ with the titania samples and Degussa P-25.

\begin{tabular}{lcc}
\hline Sample ID & $\begin{array}{c}\text { 4CP degradation } \\
\text { rate }-r_{4 \text { CF0 }} \times 10^{8} \\
(\mathrm{~mol} / \mathrm{g} \text { seg })\end{array}$ & Removal of 4CP (\%) \\
\hline AE3 & 6.30 & 69 \\
AE4 & 2.47 & 62 \\
AB3 & 8.85 & 67 \\
AB4 & 3.93 & 60 \\
RE3 & 3.92 & 75 \\
RE4 & 7.00 & 80 \\
RB3 & 10.27 & 86 \\
RB4 & 4.68 & 93 \\
FR3 & 5.94 & 77 \\
FR4 & 4.42 & 82 \\
SR3 & 10.46 & 95 \\
SR4 & 13.54 & 100 \\
Degussa P-25 & 6.97 & 57 \\
\hline
\end{tabular}

irradiation. Although mesoporous titania samples dried at room temperature showed the same average pore diameter of $3.4 \mathrm{~nm}$, in Figure 6(a) it is evident that there are differences in the percentages of $4 \mathrm{CP}$ degradation due to different specific surface areas. For mesoporous titania samples dried in a rotary evaporator, the highest percentage of degradation (approximately 93\%) was obtained with the highest average pore diameter of $4.9 \mathrm{~nm}$ (sample RB4), despite not having the largest specific surface area.

The mesoporous titania samples synthesized with different drying rate in a rotary evaporator (Figure 6(c)) degraded approximately $77-100 \%$ of 4 CP. In Figure 6(c) it is evident that the increase in the percentage of degradation of $4 \mathrm{CP}$ is related to the increase in average pore diameters of synthesized samples, since the sample SR4 (average pore diameter of $5.6 \mathrm{~nm}$ and specific surface area of $108 \mathrm{~m}^{2} \mathrm{~g}^{-1}$ ) achieves $100 \%$ of $4 \mathrm{CP}$ degradation in 180 minutes and the sample SR3 achieved only $95 \%$ of degradation at the same time, despite having higher specific surface area $\left(147 \mathrm{~m}^{2} \mathrm{~g}^{-1}\right)$ and smaller average pore diameter of $4.9 \mathrm{~nm}$. The ordered pore architecture of the mesoporous samples as compared to Degussa P-25 may result in higher diffusion rates of the guest molecules, and therefore the photocatalytic reaction rate increases. The benefits of having an ordered mesopore structure for photocatalytic applications have been demonstrated by independent research groups [46-48].

Table 3 shows the initial rates of degradation of $4 \mathrm{CP}$ for all samples synthesized and Degussa P-25. No effect of the average pore diameter was observed on the initial rate of degradation for the samples dried at room temperature. This may be due to several factors such as crystal size, because, when this decreases, the surface density of active sites available for substrate adsorption increases, thus increasing the photocatalytic reaction rate $[49,50]$.

Figure 7 shows the removal of 4CP by photocatalysis, adsorption, and photolysis using mesoporous titania sample 


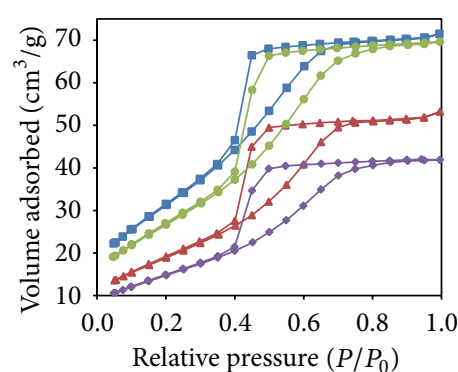

$-\mathrm{AE} 3 \rightarrow \mathrm{AB} 3$ $\rightarrow$ AE $\rightarrow$ AB 4

(a)

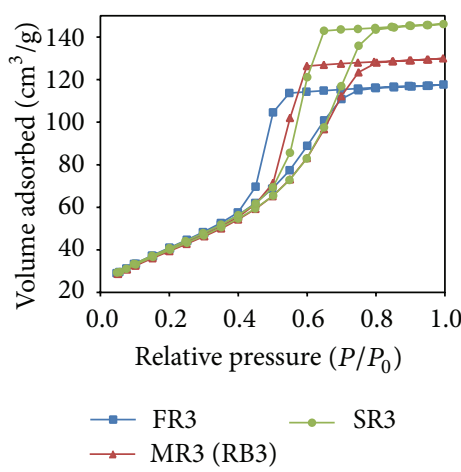

(c)
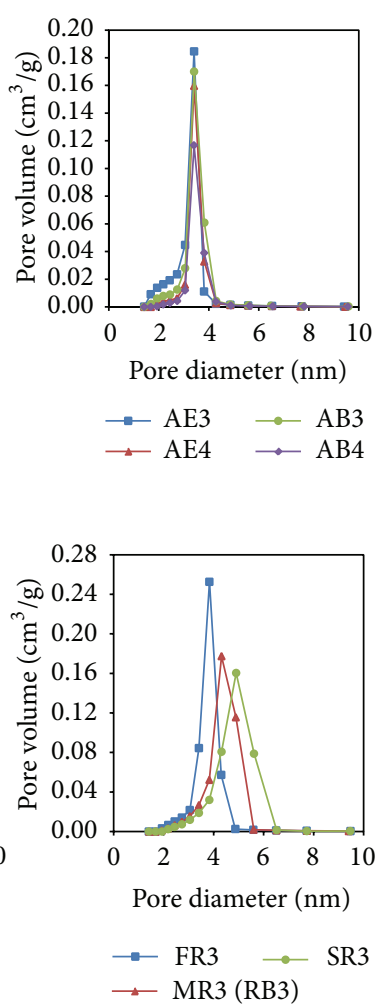

$\because \mathrm{AE} 3 \multimap \mathrm{AB} 3$

$\rightarrow \mathrm{AE} 4 \rightarrow \mathrm{AB} 4$

$\rightarrow \mathrm{MR} 3(\mathrm{RB} 3)$

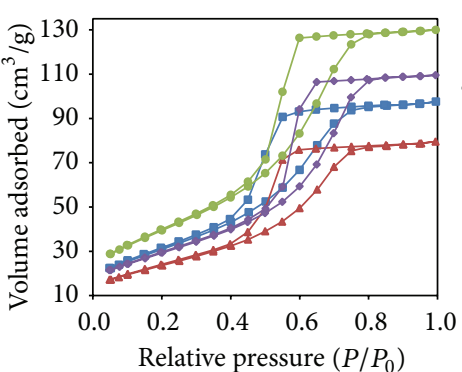

$\because \mathrm{RE} 3 \quad \rightarrow \mathrm{RB} 3$

$\rightarrow$ RE4 $\rightarrow$ RB4

(b)
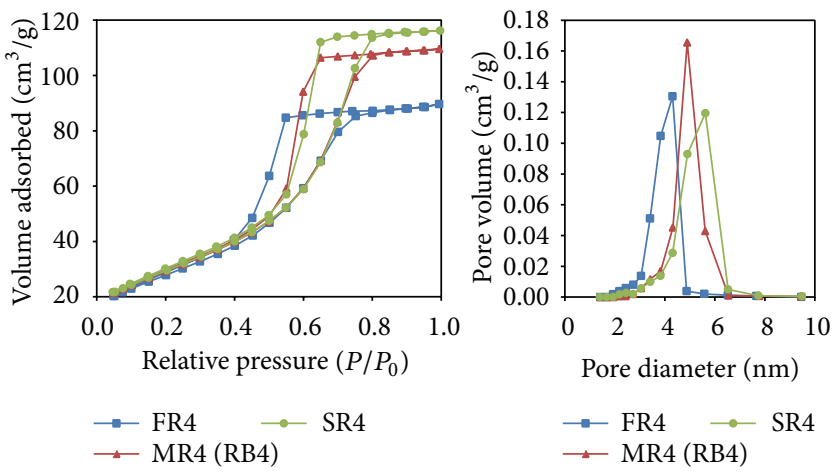

(d)

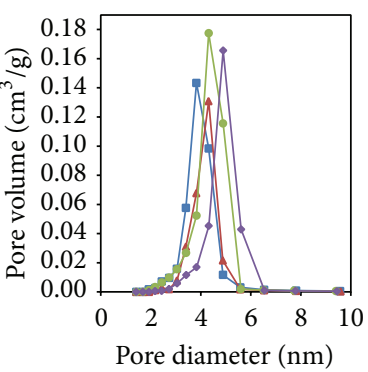

$\because \mathrm{RE} 3 \quad \cdots \mathrm{RB} 3$

$\rightarrow$ RE4 $\rightarrow$ RB4

FIGURE 3: $\mathrm{N}_{2}$ adsorption-desorption isotherms and pore size distribution of the mesoporous anatase phases dried (a) at room temperature (b) in rotary evaporator (c) with different rate in rotary evaporator and calcined at $350^{\circ} \mathrm{C}$ (d) with different rate in rotary evaporator calcined at $400^{\circ} \mathrm{C}$

TABLE 4: Apparent constant, half-life, and linearization coefficient for the Langmuir-Hinshelwood model for 4CP photodegradation.

\begin{tabular}{lccc}
\hline Sample ID & $k_{\text {ap }}$ & $t_{1 / 2}(\mathrm{~min})$ & $r^{2}$ \\
\hline AE3 & 6.60 & 105.0 & 0.948 \\
AE4 & 5.69 & 121.8 & 0.968 \\
AB3 & 5.50 & 126.0 & 0.895 \\
AB4 & 5.46 & 127.0 & 0.920 \\
RE3 & 7.79 & 89.0 & 0.996 \\
RE4 & 8.52 & 81.3 & 0.968 \\
RB3 & 11.02 & 63.0 & 0.981 \\
RB4 & 14.68 & 47.2 & 0.997 \\
FR3 & 8.57 & 80.9 & 0.976 \\
FR4 & 9.53 & 72.7 & 0.970 \\
SR3 & 15.85 & 43.7 & 0.987 \\
SR4 & 27.07 & 25.6 & 0.996 \\
Degussa P-25 & 4.40 & 157.5 & 0.864 \\
\hline
\end{tabular}

SR4 since $100 \%$ of 4 CP degradation was achieved in 180 minutes. The effect of photolysis was studied by carrying out the experiment only in the presence of oxygen and UV light without mesoporous titania. The degradation of $4 \mathrm{CP}$ by direct photolysis is negligible, and the increase in concentration is due to an electronic effect that modifies the UV absorbance spectrum and appears as if it was an increase in concentration (Figure 8). This phenomenon has been described as a photoinduction period associated with reactions involving the formation of free radicals [51-53]. Furthermore, the removal of $4 \mathrm{CP}$ by adsorption is considered negligible (Figure 7).

The kinetics of photocatalytic reactions of organic compounds are usually adequately described by the LangmuirHinshelwood model $[29,51]$. It relates the degradation rate 


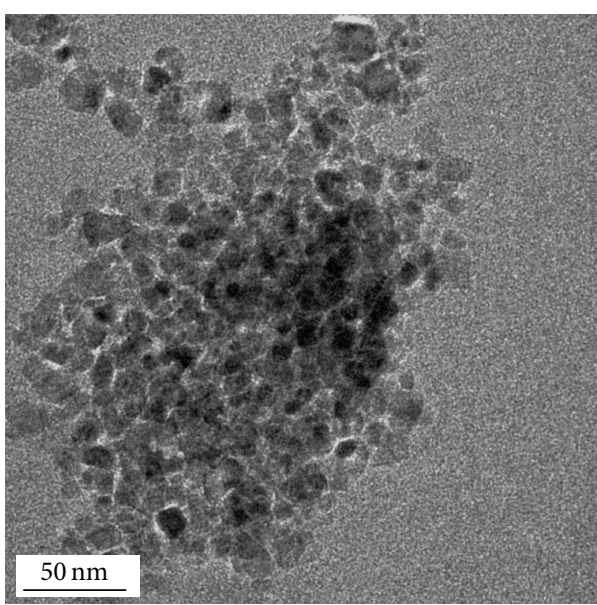

(a)

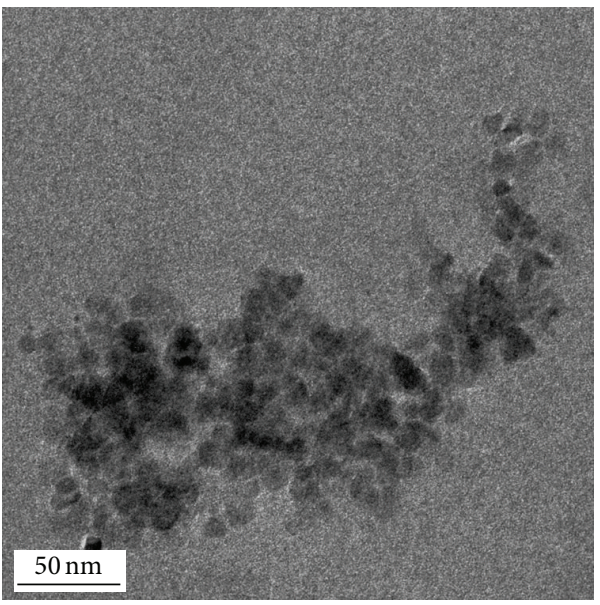

(c)

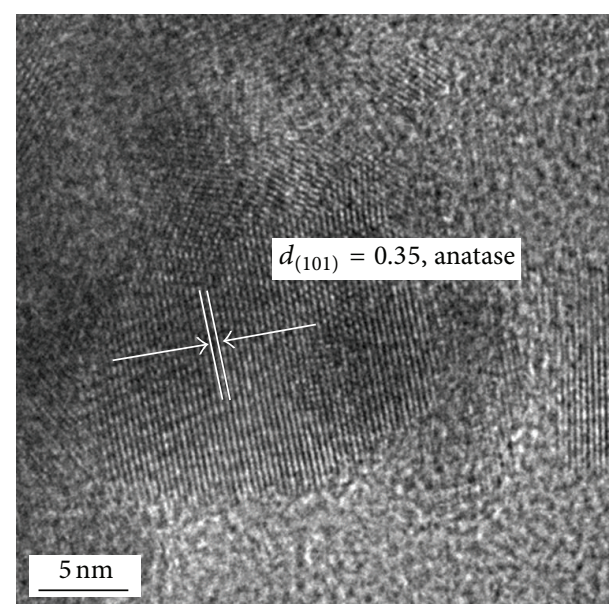

(b)

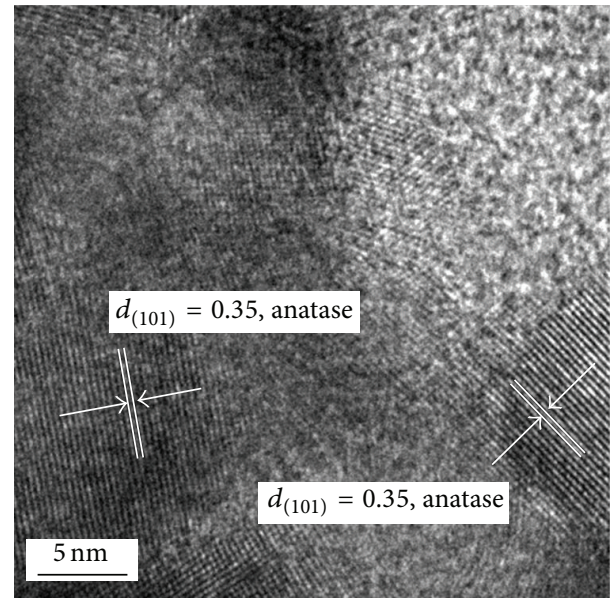

(d)

FIGURE 4: (a) and (c) TEM images of mesoporous nanocrystalline anatase samples AB4 and SR4. (b) A magnified image of (a) and (d) a magnified image of (c) with the $d$-spacing $\left(\begin{array}{lll}1 & 0 & 1\end{array}\right)$ of anatase form of titania.

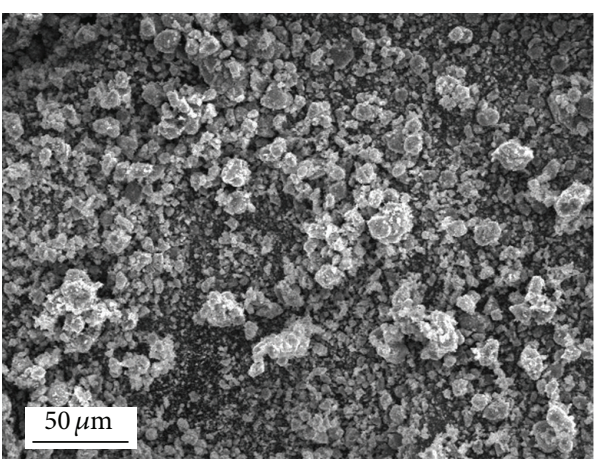

(a)

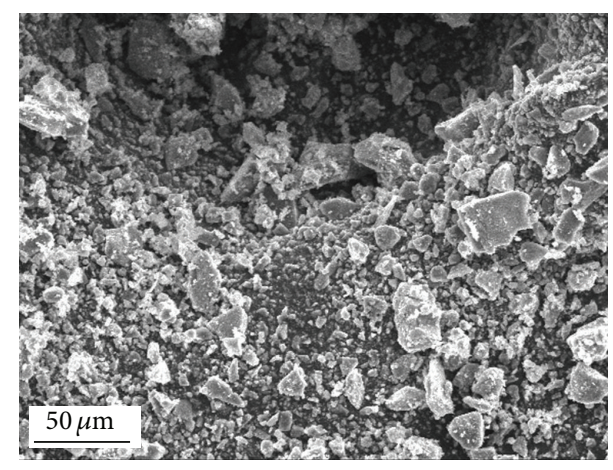

(b)

FIGURE 5: SEM images of the mesoporous anatase phases (a) SR4 (b) AB4.

$r$ and the concentration of organic compound $C$ and is expressed as follows:

$$
r=-\frac{d C}{d t}=\frac{k_{r} K_{\mathrm{ad}} C}{1+K_{\mathrm{ad}} C}
$$

where $k_{r}$ is the intrinsic rate constant and $K_{\mathrm{ad}}$ is the adsorption equilibrium constant. If adsorption is weak and concentration of organic compounds is low, the factor $K_{\mathrm{ad}} C$ is negligible, and thus (1) can be simplified to the first-order kinetics with an apparent rate constant $\left(K_{\mathrm{ap}}=k_{r} K_{\mathrm{ad}}\right)$, 


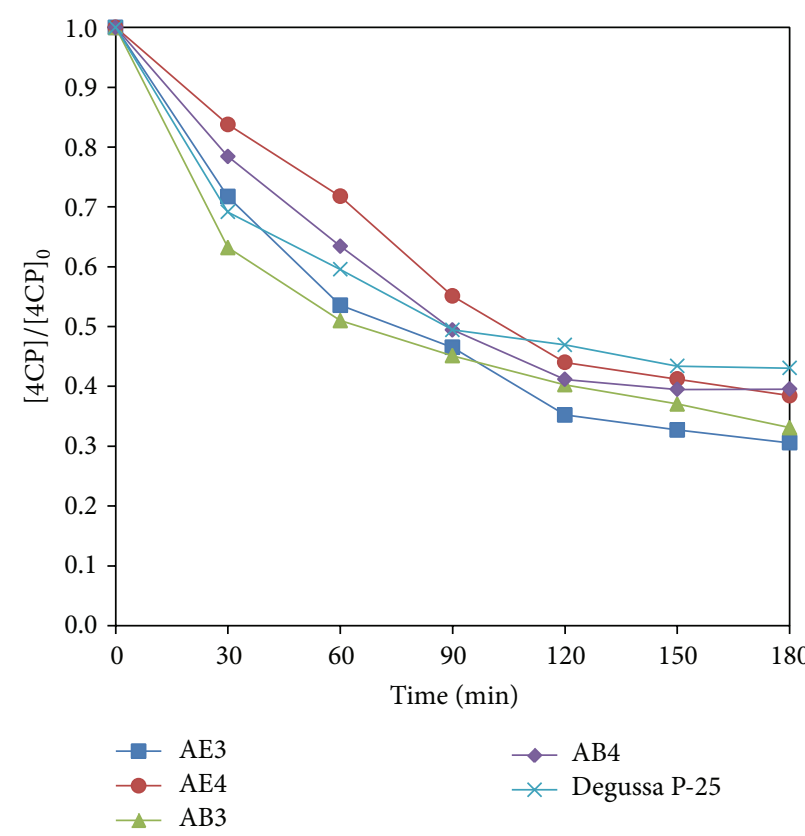

(a)

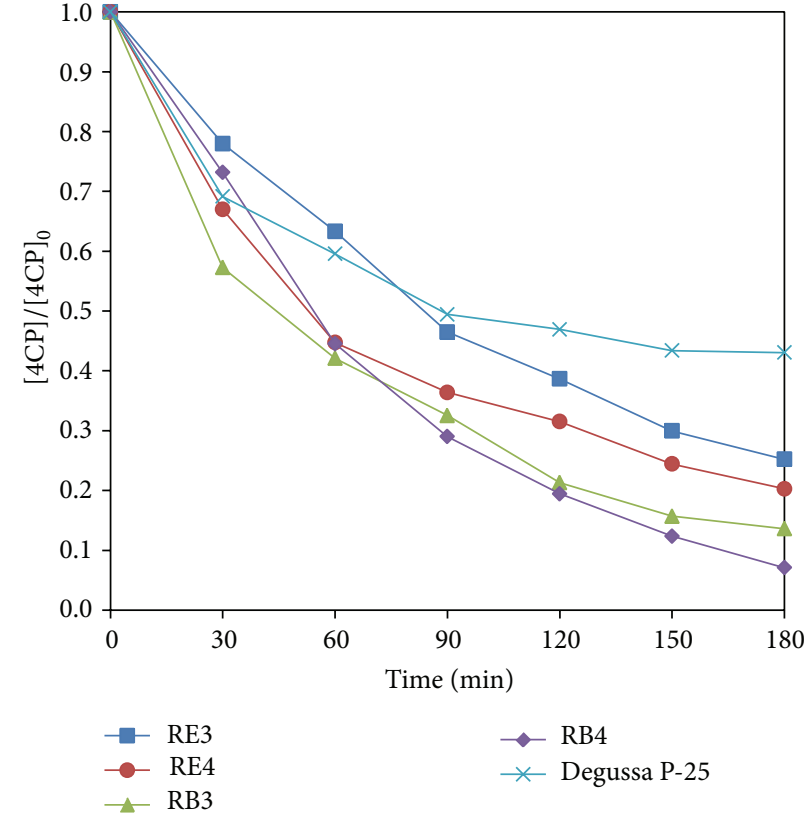

(b)

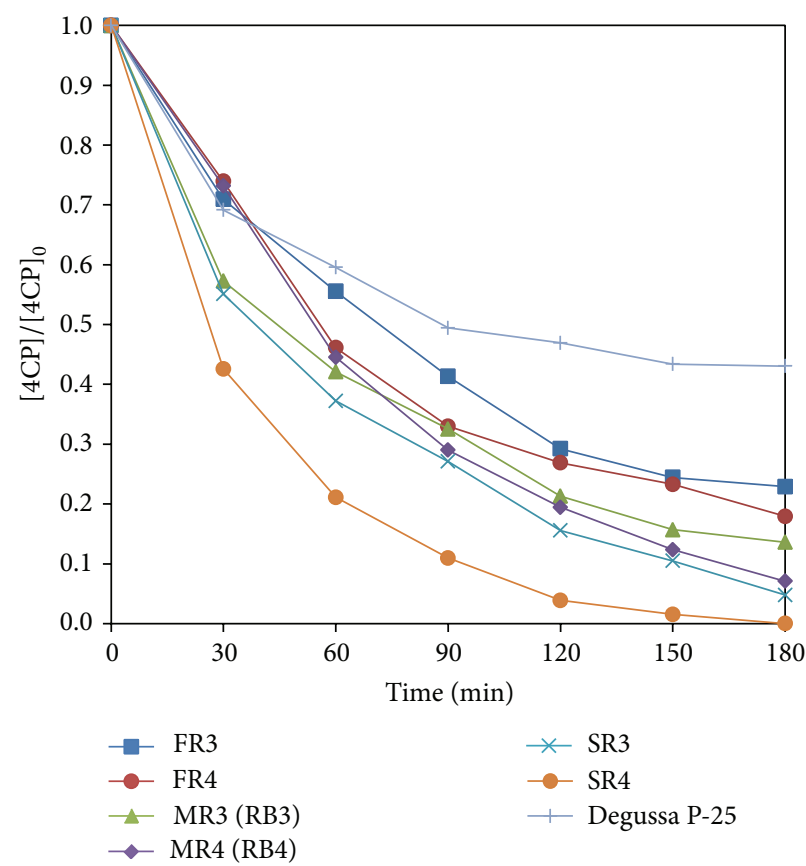

(c)

FIGURE 6: Photocatalytic degradation profiles of 4CP over the mesoporous titania samples synthesized with (a) room temperature, (b) rotary evaporator, (c) drying rate in rotary evaporator, and Degussa P-25.

which gives the following, after integration in the interval $\left[C, C_{0}\right]$ :

$$
\ln \frac{C_{0}}{C}=K_{\mathrm{ap}} t .
$$

Plotting $\ln \left(C_{0} / C\right)$ versus reaction time $t$ yields a straight line, where the slope is the apparent rate constant. The halflife of the degraded organic compound can then be easily calculated. Figure 9 shows the lineal plot of $4 \mathrm{CP}$ photodegradation, which adjusts well to a pseudo-first-order kinetic behavior. Apparent constant $K_{\text {ap }}, 4 \mathrm{CP}$ half-life, and the linearization coefficient $r^{2}$ are summarized in Table 4. 4CP half-life is as short as $25.6 \mathrm{~min}$, with mesoporous titania sample SR4, and nearly $80 \%$ of initial $0.233 \mathrm{mmol} \mathrm{L}^{-1}$ is degraded in 60 minutes. 
TABLE 5: COD values of the aqueous solution before and after photocatalytic tests, adsorption, and photolysis.

\begin{tabular}{lcc}
\hline \multirow{2}{*}{ Sample } & \multicolumn{2}{c}{ COD value (mg/L) } \\
& $\begin{array}{c}\text { Initial } \\
\text { (0 minutes) }\end{array}$ & $\begin{array}{c}\text { Final } \\
(180 \text { minutes })\end{array}$ \\
\hline SR4 (photocatalysis) & 47 & 20 \\
SR4 (adsorption) & 47 & 47 \\
Degussa P-25 (photocatalysis) & 47 & 36 \\
Photolysis & 47 & 47 \\
\hline
\end{tabular}

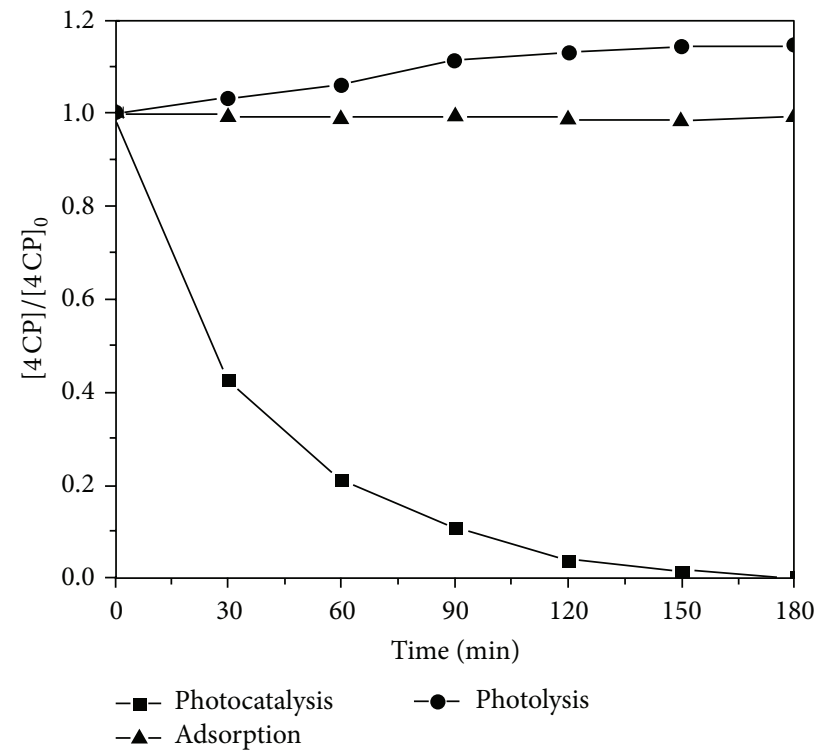

FIGURE 7: Effect of photocatalysis, adsorption, and photolysis on the removal of $4 \mathrm{CP}$ as a function of time using mesoporous titania sample SR4.

Table 5 shows the COD values to identify the presence of organic matter in the aqueous solution after photocatalytic tests. 4CP photodegradation using sample SR4 reduced the initial value of COD by $57 \%$, whereas Degussa P-25 reduced the initial value of COD by $23 \%$ after the same time of exposure to UV irradiation. These results support the removal of $4 \mathrm{CP}$ by adsorption and photolysis shown in Figure 7, without reduction in initial values of COD. Therefore, it is demonstrated that the organic compound is mineralized. In specialized literature $[34,36]$, hydroquinone (HQ), benzoquinone (BQ), and 4-chlorocatechol (4CC) have been reported as the major aromatic intermediates, identified by HPLC, LC-MS, and GC-MS techniques. Although interesting, such characterization is beyond the scope of this paper.

\section{Conclusions}

Mesoporous nanocrystalline anatase was found to provide a faster degradation rate than Degussa P-25 as consequence of different surface morphological characteristics. Among the studied variables, different drying rate in rotary evaporator

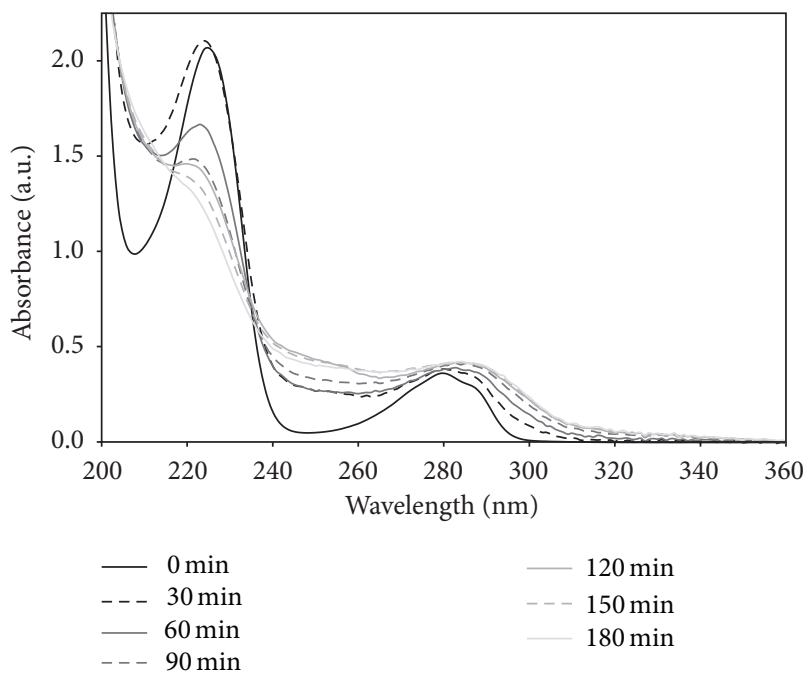

FIGURE 8: UV/Vis spectra of the 4CP degradation under photolysis.

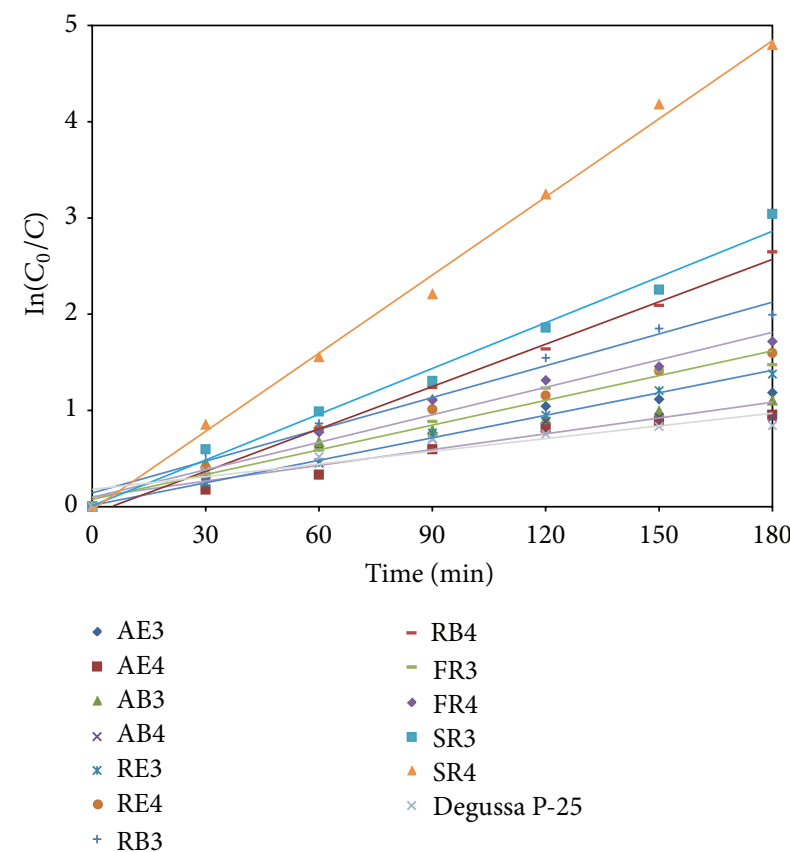

Figure 9: Pseudo-first-order kinetics degradation of 4CP, by the Langmuir-Hinshelwood model.

was determined to be the one that affects the increase in average pore diameter, and this affects both the percentage of photodegradation and the chemical oxygen demand (COD) value. The diffusion towards the active sites and the accessibility of the active sites for adsorption due to the presence of large pores are key parameters for the photocatalytic degradation of $4 \mathrm{CP}$. The photodegradation process was found to be controlled by the Langmuir-Hinshelwood model. The mesoporous anatase degraded 100\% 4CP, while Degussa P25 degraded $57 \%$. The enhanced photocatalytic activity of the 
mesoporous titania samples when compared to Degussa P-25 was related to smaller crystallite size, presence of pure anatase phase, higher average pore diameter, and surface area. The reduction of 57\% COD with mesoporous anatase compared with $23 \%$ Degussa P-25 shows that $4 \mathrm{CP}$ is mineralized.

\section{Conflict of Interests}

The authors declare that there is no conflict of interests regarding the publication of this paper.

\section{Acknowledgments}

The authors are grateful to PROMEP for financial support through Project 103.5/13/S257. Osmín Avilés-García thanks CONACYT for scholarship 290649 and CCIQS from UAEM for the granted support.

\section{References}

[1] R. W. Matthews, "Kinetics of photocatalytic oxidation of organic solutes over titanium dioxide," Journal of Catalysis, vol. 111, pp. 264-272, 1988.

[2] C. S. Turchi and D. F. Ollis, "Photocatalytic degradation of organic water contaminants: mechanisms involving hydroxyl radical attack," Journal of Catalysis, vol. 122, no. 1, pp. 178-192, 1990.

[3] D. W. Bahnemann, J. Cunningham, M. A. Fox, E. Pelizzetti, P. Pichat, and N. Serpone, "Photocatalytic treatment of waters," in Aquatic Surface and Photochemistry, R. G. Zepp, G. R. Helz, and D. G. Crosby, Eds., pp. 261-316, Lewis, Boca Raton, Fla, USA, 1994.

[4] M. R. Hoffmann, S. T. Martin, W. Choi, and D. W. Bahnemann, "Environmental applications of semiconductor photocatalysis," Chemical Reviews, vol. 95, no. 1, pp. 69-96, 1995.

[5] J.-M. Herrmann, "Heterogeneous photocatalysis: fundamentals and applications to the removal of various types of aqueous pollutants," Catalysis Today, vol. 53, no. 1, pp. 115-129, 1999.

[6] H. Yang, A. Kuperman, N. Coombs, S. Mamiche-Afara, and G. A. Ozin, "Synthesis of oriented films of mesoporous silica on mica," Nature, vol. 379, no. 6567, pp. 703-705, 1996.

[7] H. Yang, N. Coombs, I. Sokolov, and G. A. Ozin, "Free-standing and oriented mesoporous silica films grown at the air-water interface," Nature, vol. 381, no. 6583, pp. 589-592, 1996.

[8] Y. Lu, R. Ganguli, C. A. Drewien et al., "Continuous formation of supported cubic and hexagonal mesoporous films by sol-gel dip-coating," Nature, vol. 389, no. 6649, pp. 364-368, 1997.

[9] M. A. Carreon and V. V. Guliants, "Mesostructuring of metal oxides through EISA: fundamentals and applications," in Ordered Porous Solids, Chapter 16, pp. 413-439, 2009.

[10] G. J. D. A. A. Soler-Illia, A. Louis, and C. Sanchez, "Synthesis and characterization of mesostructured titania-based materials through evaporation-induced self-assembly," Chemistry of Materials, vol. 14, no. 2, pp. 750-759, 2002.

[11] K. De Witte, A. M. Busuioc, V. Meynen et al., "Influence of the synthesis parameters of $\mathrm{TiO}_{2}$-SBA-15 materials on the adsorption and photodegradation of rhodamine-6G," Microporous and Mesoporous Materials, vol. 110, no. 1, pp. 100-110, 2008.

[12] M. A. Carreon, S. Y. Choi, M. Mamak, N. Chopra, and G. A. Ozin, "Pore architecture affects photocatalytic activity of periodic mesoporous nanocrystalline anatase thin films," Journal of Materials Chemistry, vol. 17, no. 1, pp. 82-89, 2007.

[13] M. L. Carreon, H. G. Carreon, J. Espino-Valencia, and M. A. Carreon, "Photocatalytic degradation of organic dyes by mesoporous nanocrystalline anatase," Materials Chemistry and Physics, vol. 125, no. 3, pp. 474-478, 2011.

[14] R. Andreozzi and R. Marotta, "Ozonation of p-chlorophenol in aqueous solution," Journal of Hazardous Materials, vol. 69, no. 3, pp. 303-317, 1999.

[15] C. H. Kuo and C. H. Huang, "Aqueous phase ozonation of chlorophenols," Journal of Hazardous Materials, vol. 41, no. 1, pp. 31-45, 1995.

[16] Y. Pi, L. Zhang, and J. Wang, "The formation and influence of hydrogen peroxide during ozonation of para-chlorophenol," Journal of Hazardous Materials, vol. 141, no. 3, pp. 707-712, 2007.

[17] M. L. Satuf, R. J. Brandi, A. E. Cassano, and O. M. Alfano, "Photocatalytic degradation of 4-chlorophenol: a kinetic study," Applied Catalysis B: Environmental, vol. 82, no. 1-2, pp. 37-49, 2008.

[18] J.-C. D’Oliveira, G. Al-Sayyed, and P. Pichat, "Photodegradation of 2- and 3-chlorophenol in $\mathrm{TiO}_{2}$ aqueous suspensions," Environmental Science and Technology, vol. 24, no. 7, pp. 990-996, 1990.

[19] T. Pandiyan, O. M. Rivas, J. O. Martínez, G. B. Amezcua, and M. A. M. Carrillo, "Comparison of methods for the photochemical degradation of chlorophenols," Journal of Photochemistry and Photobiology A: Chemistry, vol. 146, pp. 149-155, 2002.

[20] J.-C. D’Oliveira, C. Minero, E. Pelizzetti, and P. Pichat, "Photodegradation of dichlorophenols and trichlorophenols in $\mathrm{TiO}_{2}$ aqueous suspensions: kinetic effects of the positions of the $\mathrm{Cl}$ atoms and identification of the intermediates," Journal of Photochemistry and Photobiology A: Chemistry, vol. 72, no. 3, pp. 261-267, 1993.

[21] K. H. Wang, Y. H. Hsieh, M. Y. Chou, and C. Y. Chang, "Photocatalytic degradation of 2-chloro and 2-nitrophenol by titanium dioxide suspensions in aqueous solution," Applied Catalysis B: Environmental, vol. 21, pp. 1-8, 1999.

[22] Y.-C. Chan, J.-N. Chen, and M.-C. Lu, "Intermediate inhibition in the heterogeneous UV-catalysis using a $\mathrm{TiO}_{2}$ suspension system," Chemosphere, vol. 45, no. 1, pp. 29-35, 2001.

[23] A. M. Peiró, J. A. Ayllón, J. Peral, and X. Doménech, " $\mathrm{TIO}_{2}-$ photocatalyzed degradation of phenol and ortho-substituted phenolic compounds," Applied Catalysis B: Environmental, vol. 30, pp. 359-373, 2001.

[24] U. Stafford, K. A. Gray, and P. V. Kamat, "Photocatalytic degradation of 4-chlorophenol: the effects of varying $\mathrm{TiO}_{2}$ concentration and light wavelength," Journal of Catalysis, vol. 167, no. 1, pp. 25-32, 1997.

[25] U. Stafford, K. A. Gray, and P. V. Kamat, "Radiolytic and $\mathrm{TiO}_{2}$-assisted photocatalytic degradation of 4-chlorophenol. A comparative study," Journal of Physical Chemistry, vol. 98, no. 25, pp. 6343-6351, 1994.

[26] A. Mills and J. Wang, "Photomineralisation of 4-chlorophenol sensitised by $\mathrm{TiO}_{2}$ thin films," Journal of Photochemistry and Photobiology A: Chemistry, vol. 118, pp. 53-63, 1998.

[27] X. Li, J. W. Cubbage, T. A. Tetzlaff, and W. S. Jenks, "Photocatalytic degradation of 4-chlorophenol. 1. The hydroquinone pathway," Journal of Organic Chemistry, vol. 64, no. 23, pp. 8509-8524, 1999.

[28] X. Li, J. W. Cubbage, and W. S. Jenks, "Photocatalytic degradation of 4-chlorophenol. 2. The 4-chlorocatechol pathway," 
Journal of Organic Chemistry, vol. 64, no. 23, pp. 8525-8536, 1999.

[29] E. M. Campo, J. S. Valente, T. Pavón, R. Romero, Á. Mantilla, and R. Natividad, "4-chlorophenol oxidation photocatalyzed by a calcined $\mathrm{Mg}-\mathrm{Al}-\mathrm{Zn}$ layered double hydroxide in a co-current downflow bubble column," Industrial \& Engineering Chemistry Research, vol. 50, pp. 11544-11552, 2011.

[30] H. Al-Ekabi, N. Serpone, E. Pelizzetti, C. Minero, M. A. Fox, and R. B. Draper, "Kinetic studies in heterogeneous photocatalysis. 2. $\mathrm{TiO}_{2}$-mediated degradation of 4-chlorophenol alone and in a three-component mixture of 4-chlorophenol, 2,4dichlorophenol, and 2,4,5-trichlorophenol in air-equilibrated aqueous media," Langmuir, vol. 5, no. 1, pp. 250-255, 1989.

[31] R. W. Matthews, "Purification of water with near-U.V. illuminated suspensions of titanium dioxide," Water Research, vol. 24, no. 5, pp. 653-660, 1990.

[32] G. Al-Sayyed, J. C. D'Oliveira, and P. Pichat, "Semiconductorsensitized photodegradation of 4-chlorophenol in water," Journal of Photochemistry and Photobiology A: Chemistry, vol. 58, pp. 99-114, 1991.

[33] A. Mills, S. Morris, and R. Davies, "Photomineralisation of 4chlorophenol sensitised by titanium dioxide: a study of the intermediates," Journal of Photochemistry and Photobiology A: Chemistry, vol. 70, pp. 183-191, 1993.

[34] A. Mills and S. Morris, "Photomineralization of 4-chlorophenol sensitized by titanium dioxide: a study of the initial kinetics of carbon dioxide photogeneration," Journal of Photochemistry and Photobiology A: Chemistry, vol. 71, pp. 75-83, 1993.

[35] J. Theurich, M. Lindner, and D. W. Bahnemann, "Photocatalytic degradation of 4-chlorophenol in aerated aqueous titanium dioxide suspensions: a kinetic and mechanistic study," Langmuir, vol. 12, no. 26, pp. 6368-6376, 1996.

[36] M. Hügül, I. Boz, and R. Apak, "Photocatalytic decomposition of 4-chlorophenol over oxide catalysts," Journal of Hazardous Materials, vol. 64, no. 3, pp. 313-322, 1999.

[37] M. Fröba, O. Muth, and A. Reller, "Mesostructured $\mathrm{TiO}_{2}$ : ligand-stabilized synthesis and characterization," Solid State Ionics, vol. 101-103, no. 1, pp. 249-253, 1997.

[38] S. Cabrera, J. El Haskouri, A. Beltrán-Porter, D. Beltrán-Porter, M. D. Marcos, and P. Amorós, "Enhanced surface area in thermally stable pure mesoporous $\mathrm{TiO}_{2}$," Solid State Sciences, vol. 2, pp. 513-518, 2000.

[39] A. Gibaud, D. Grosso, B. Smarsly et al., "Evaporation-controlled self-assembly of silica surfactant mesophases," Journal of Physical Chemistry B, vol. 107, no. 25, pp. 6114-6118, 2003.

[40] T. Hongo and A. Yamazaki, "Thermal influence on the structure and photocatalytic activity of mesoporous titania consisting of $\mathrm{TiO}_{2}$ (B)," Microporous and Mesoporous Materials, vol. 142, no. 1, pp. 316-321, 2011.

[41] E. L. Crepaldi, G. J. D. A. A. Soler-Illia, D. Grosso, F. Cagnol, F. Ribot, and C. Sanchez, "Controlled formation of highly organized mesoporous titania thin films: from mesostructured hybrids to mesoporous nanoanatase $\mathrm{TiO}_{2}$," Journal of the American Chemical Society, vol. 125, no. 32, pp. 9770-9786, 2003.

[42] K. S. W. Sing, D. H. Everett, R. A. W. Haul et al., "Reporting physisorption data for gas/solid systems with special reference to the determination of surface area and porosity (Recommendations 1984)," Pure and Applied Chemistry, vol. 57, pp. 603-619, 1985.

[43] T. Ohno, K. Sarukawa, K. Tokieda, and M. Matsumura, "Morphology of a $\mathrm{TiO}_{2}$ photocatalyst (Degussa, P-25) consisting of anatase and rutile crystalline phases," Journal of Catalysis, vol. 203, no. 1, pp. 82-86, 2001.

[44] A. Katti, S. R. Venna, and M. A. Carreon, "Self-assembly hydrothermal assisted synthesis of mesoporous anatase in the presence of ethylene glycol," Catalysis Communications, vol. 10, no. 15, pp. 2036-2040, 2009.

[45] A. Mills and S. LeHunte, "An overview of semiconductor photocatalysis," Journal of Photochemistry and Photobiology A: Chemistry, vol. 108, pp. 1-35, 1997.

[46] Y. Sakatani, D. Grosso, L. Nicole, C. Boissiere, G. J. D. A. A. Soller-Illia, and C. Sanchez, "Optimised photocatalytic activity of grid-like mesoporous $\mathrm{TiO}_{2}$ films: effect of crystallinity, pore size distribution, and pore accessibility," Journal of Materials Chemistry, vol. 16, pp. 77-82, 2006.

[47] K. De Witte, S. Ribbens, V. Meynen et al., "Photocatalytic study of P25 and mesoporous titania in aqueous and gaseous environment," Catalysis Communications, vol. 9, no. 8, pp. 17871792, 2008.

[48] E. Beyers, P. Cool, and E. F. Vansant, "Stabilisation of mesoporous $\mathrm{TiO}_{2}$ by different bases influencing the photocatalytic activity," Microporous and Mesoporous Materials, vol. 99, no. 12, pp. 112-117, 2007.

[49] J. W. Moon, C. Y. Yun, and K. W. Chung, "Photocatalytic activation of $\mathrm{TiO}_{2}$ under visible light using Acid Red 44," Catalysis Today, vol. 87, pp. 77-86, 2003.

[50] E. P. Reddy, B. Sun, and P. G. Smiriniotis, "Transition metal modified $\mathrm{TiO}_{2}$-loaded MCM-41 catalysts for visible- and UVlight driven photodegradation of aqueous organic pollutants," The Journal of Physical Chemistry B, vol. 108, pp. 17198-17205, 2004.

[51] J. S. Valente, F. Tzompantzi, J. Prince, J. G. H. Cortez, and R. Gomez, "Adsorption and photocatalytic degradation of phenol and 2,4 dichlorophenoxiacetic acid by $\mathrm{Mg}$ - Zn-Al layered double hydroxides," Applied Catalysis B: Environmental, vol. 90, no. 3-4, pp. 330-338, 2009.

[52] J. S. Valente, F. Tzompantzi, and J. Prince, "Highly efficient photocatalytic elimination of phenol and chlorinated phenols by $\mathrm{CeO}_{2} / \mathrm{MgAl}$ layered double hydroxides," Applied Catalysis $\mathrm{B}$ : Environmental, vol. 102, no. 1-2, pp. 276-285, 2011.

[53] G. Sivalingam, M. H. Priya, and G. Madras, "Kinetics of the photodegradation of substituted phenols by solution combustion synthesized $\mathrm{TiO}_{2}$," Applied Catalysis B: Environmental, vol. 51, no. 1, pp. 67-76, 2004. 

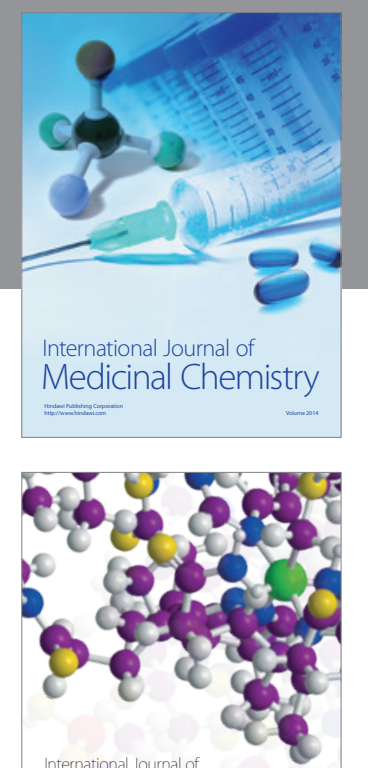

\section{Carbohydrate} Chemistry

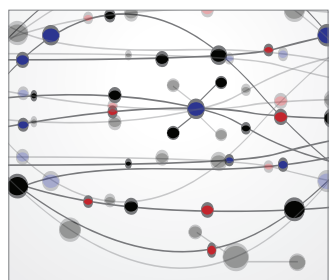

The Scientific World Journal
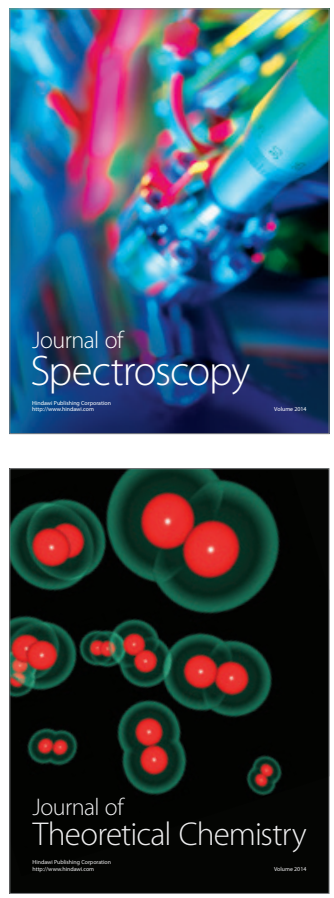
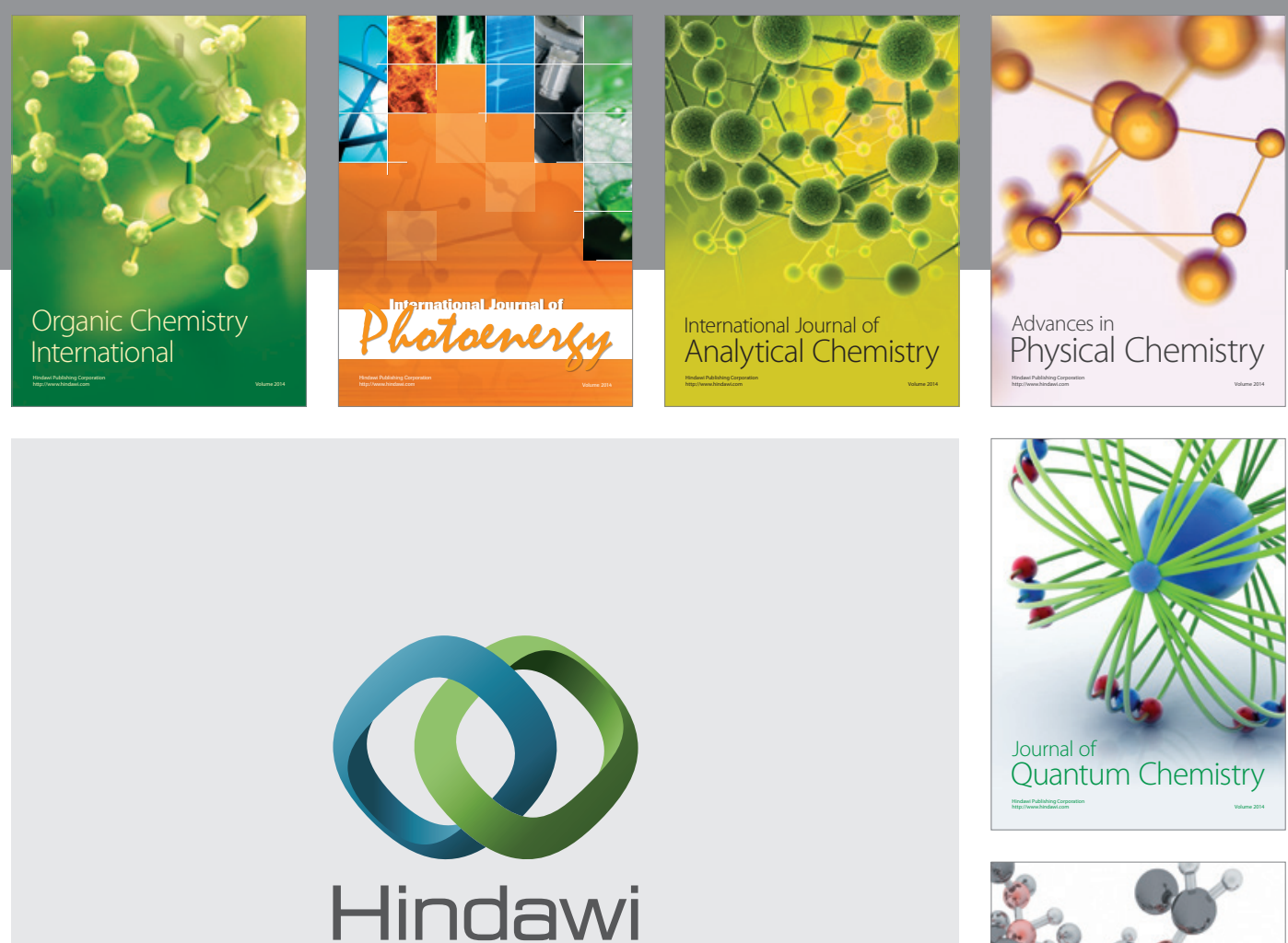

Submit your manuscripts at

http://www.hindawi.com

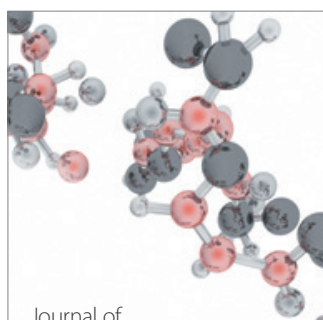

Analytical Methods

in Chemistry

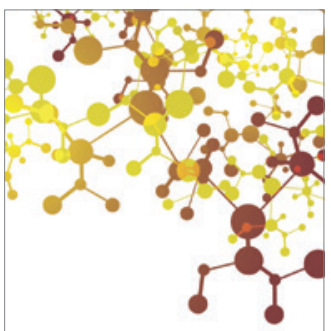

Journal of

Applied Chemistry

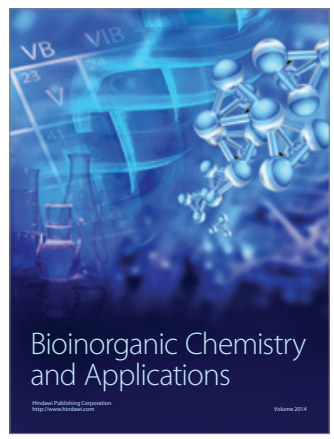

Inorganic Chemistry
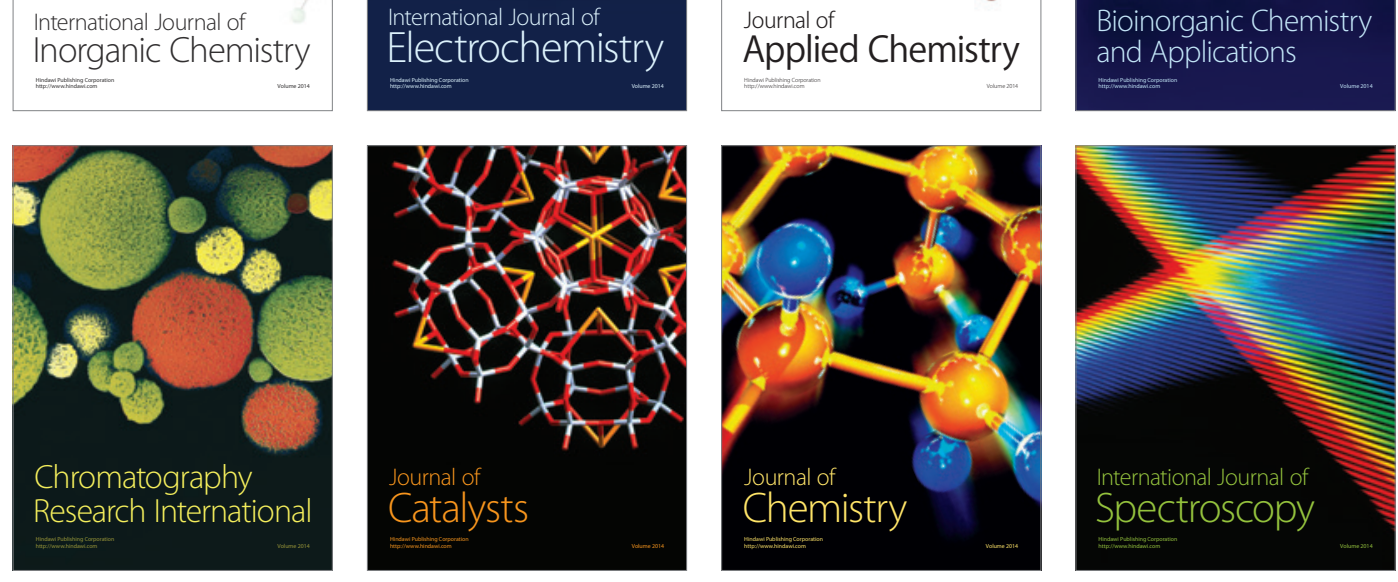